\title{
UNVEILING THE INDUSTRY 4.0 CONCEPT AND THE USE OF ITS TECHNOLOGIES
}

\author{
Felipe Fernando da Silva Vieira ${ }^{1}$, Manoel Henrique Reis Nascimento², Caio César Lacerda \\ Figueiredo $^{3}$, Aline Santos do Nascimento ${ }^{4}$
}

\author{
${ }^{1,2,3}$ Fundação Centro de Análise e Pesquisa e Inovação Tecnológica (FUCAPI) - Av. Gov. Danilo de Matos Aerosa, 381 - \\ Distrito Industrial, Manaus - AM. \\ ${ }^{4}$ Ciências Naturais, Universidade Federal do Amazonas (UFAM), Brasil.
}

Email: felipe fernando@live.com, hreys@bol.com.br, kaio.cesr@gmail.com, alynne_santos2000@hotmail.com

Received: May 22th 2019

Accepted: May 24th 2019

Published: September $30^{\text {th }}$, 2019

Copyright @ 2016 by authors and Institute of Technology Galileo of Amazon (ITEGAM). This work is licensed under the Creative Commons Attribution International License (CC BY 4.0). https://creativecommons.org/lice nses/by/4.0/

\begin{abstract}
One of the most commented subjects currently in companies that are looking for excellence is certainly the Industry 4.0. A technological advance that if not implemented in a successful way can cause the loss of competitiveness and non-survival of the company, on the contrary can make it a reference in the current market. It is natural that with the advancement of any segment we have doubts regarding its approach. The purpose of this article is to describe the concepts, applications and maturity levels of Industry 4.0, as well as to clarify its degree of maturity in relation to industrial automation that is also part of this concept, but that did not emerge from it. It also presents the main enabling technologies that drive it, its relevance and interaction in the industry and examples of companies that in Brazil are already applying the concepts of the current revolution and the technologies that characterize it.
\end{abstract}

Keywords: Industry 4.0, Internet of Things, Maturity, Advanced Manufacturing

\section{DESVENDANDO O CONCEITO INDÚSTRIA 4.0 E O USO DE SUAS TECNOLOGIAS}

\section{RESUMO}

Um dos assuntos mais comentados atualmente nas empresas que buscam a excelência sem dúvida é a indústria 4.0. Um avanço tecnológico que se não implementado de forma bem sucedida pode causar a perda de competitividade e a não sobrevivência da empresa, ao contrário pode torná-la referência no mercado atual. É natural que com o avanço de qualquer segmento tenhamos dúvidas com relação a sua abordagem. O objetivo deste artigo é descrever os conceitos, aplicações e os níveis de maturidade da indústria 4.0, como também esclarecer o seu grau de maturidade em relação a automação industrial que também faz parte deste conceito, mas que não surgiu a partir dele. Também apresenta, as principais tecnologias habilitadoras que a impulsionam, sua relevância e interação na indústria e exemplos de empresas que no Brasil já estão aplicando os conceitos da revolução atual e as tecnologias que à caracterizam.

Palavras-chaves: Indústria 4.0, Internet das Coisas, Maturidade, Manufatura Avançada. 


\section{INTRODUÇÃO}

Estamos vivendo na era digital, o mundo vive em constantes mudanças e devemos levar como obrigação a reciclagem dos nossos conhecimentos e de nossos processos, para que estejamos aptos a nos adequar diante dessas transições. O avanço da tecnologia é o grande causador dessas mudanças, sendo assim, não deve ser tratada como uma simples questão de escolha, é notório que tudo gira em torno dela, portanto, é imprescindível que devemos utilizar de ferramentas tecnológicas no cenário em que vivemos hoje.

A expansão tecnológica tem sido um dos fatores de grande importância para a sobrevivência das indústrias. Grandes empresas chegaram a falência por não implantarem a cultura da inovação ou implantação de maneira não consciente, pois parte desse insucesso está ligado a utilização inadequada ou até mesmo a não utilização dessas ferramentas. E para que não aconteça desastres desse tipo, a melhor saída é sempre está aberto a inovações, reinventar seus negócios e processos.

Inovar é ponto crucial para que empresas mantenham-se erguida e competitiva, e dependendo do segmento corporativo como chão de fábrica, é impossível que sobrevivam sem o uso das tecnologias, pois necessitam de agilidade e qualidade em seus processos para que atendam as demandas e a satisfação de seus clientes. E a inovação não se restringe apenas as indústrias, como também obriga as pessoas a se inovarem, com a possível extinção de algumas profissões e o surgimento de novas, em um futuro próximo e promissor.

Pensando nisso, o artigo tem como propósito apresentar o ponto em que chegamos para que toda essa inclusão tecnológica passasse a se tornar uma obrigação não só para as indústrias, mas também para as pessoas, através da abordagem de um breve resumo desde o surgimento da primeira revolução industrial até o novo conceito revolucionário do momento chamado de Indústria 4.0. Quais foram as principais características de cada fase da indústria que causaram grandes impactos para serem consideradas como 'revoluções'. Para a quarta revolução industrial, quais são as tecnologias habilitadoras, como elas estão integradas nessa fase e quais tecnologias estão causando o grande diferencial no mercado atual e exemplos desse novo conceito tecnológico aplicados no Brasil.

\section{O QUE É A INDÚSTRIA 4.0?}

O termo indústria 4.0 surgiu na Alemanha em 2011, na feira Hannover Messe, líder mundial em automação industrial. Foi apresentado como projeto estratégico e de alta tecnologia para promover a manufatura alemã e impulsionar suas exportações. $\mathrm{O}$ conceito agrega as principais inovações tecnológicas para diversos segmentos que se aplicam em processos de fabricação e serviços.

$\mathrm{O}$ que todos esses termos têm em comum é o reconhecimento de que os métodos tradicionais de manufatura e produção estão no meio de uma transformação digital. Há algum tempo, o processo industrial adota cada vez mais a moderna tecnologia da informação (TI), mas as tendências mais recentes do processo vão além da automação da produção que, desde o início dos anos 70, foi impulsionada pelos desenvolvimentos em eletrônica e TI [1].

\section{REFERENCIAL TEÓRICO}

\section{III.1 O CAMINHO ATÉ A INDÚSTRIA 4.0}

Indústria 4.0 significa que esta é a quarta revolução industrial do mundo, sucessora de três revoluções industriais anteriores que causaram grandes saltos na produtividade e mudou a vida das pessoas em todo o mundo [2].

\section{EVOLUÇÃO DA INDÚSTRIA}

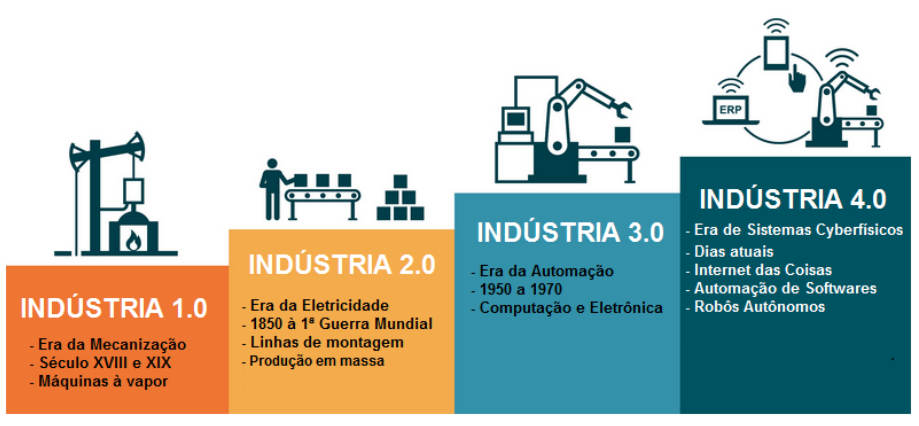

Figura 1: Evolução Industrial.

Fonte: [3].

A seguir uma curta síntese que explana o que foi a evolução das indústrias com foco em suas principais características que as denominaram como revoluções industriais:

1' Revolução Industrial: A primeira "Revolução Industrial", começou no Reino Unido no final do século XVIII e terminou em meados do século XIX. Representou a mudança de uma economia agrária, à base de artesanato, para uma economia liderada pela indústria e pela fabricação de máquinas com a introdução de métodos de produção mecânica e a aplicação de energia a vapor [4].

As características mais significativas desse período foram a substituição do trabalho artesanal por assalariado, uma nova concepção do trabalho diminuindo esforços humanos e concentrando em máquinas, o que era manual começou a se tornar mecânico, a utilização das máquinas a vapor e o desenvolvimento de produtos químicos.

$\mathbf{2}^{\circ}$ Revolução Industrial: A segunda revolução industrial foi um progresso científico e tecnológico que ocorreu na Inglaterra, França e Estados Unidos.

$\mathrm{O}$ segundo período teve início no princípio do século $\mathrm{XX}$. Foi marcado pela era da produção industrial em massa, na qual princípios da linha de montagem eram voltados para criação de produtos de consumo em massa. A introdução da energia elétrica auxiliou o conjunto de mudanças [4].

Henry Ford da indústria automobilística Ford implantada nos Estados Unidos, mudava então os rumos das indústrias com o modelo de produção em série, com a utilização de esteiras que transportavam as peças dos carros em fabricação.

Os operários montavam os carros com as peças que chegavam em suas mãos em outra esteira. Esse método de racionalização de produção foi denominado de fordismo [5].

$3^{\circ}$ Revolução Industrial: A terceira revolução iniciada na década de 70 é marcada pela automatização dos processos de produção com a implantação de produtos eletrônicos e TI em processos industriais [4].

Os avanços foram imensos, principalmente no desenvolvimento de softwares, uso de Controladores Lógicos 
Programáveis (CLPs), nos campos da microeletrônica, robótica, transistores, circuitos eletrônicos, telecomunicações e da informática, no geral [6].

Nesse período a computação e a robótica foram os destaques nas indústrias. Observou-se a revolução dos transmissores de Rádio e TV, a internet conectando o mundo, a telefonia fixa que mais tarde tornava-se telefonia móvel, o conhecimento da indústria aeroespacial, biotecnologia, nanotecnologia e muitas outras inovações. As tecnologias dessa revolução estão sendo usadas como base para a quarta revolução industrial.

$4^{0}$ Revolução Industrial: Durante a próxima década, a quarta revolução industrial dará início a uma era de produção "descentralizada". O uso de tecnologia de sensores, interconectividade e análise de dados permitirá a fusão dos mundos reais e virtuais na produção [4].

Em outras palavras, a quarta revolução é um conjunto de elementos tecnológicos que integrados se beneficiam da redução dos limites entre o mundo virtual e o mundo físico, o que permite trabalhos colaborativos entre humanos e máquinas. Um de seus componentes chaves é a utilização de sistemas de produção cyberfísicos (CPS).

Nas palavras de [7], "estamos no início de uma revolução que está mudando fundamentalmente a forma em que vivemos, trabalhamos e nos relacionamos um com outro". Referindo-se ao novo modelo de interação e trabalho que será implantado dando início as indústrias inteligentes.

As transformações associadas ao conceito da Indústria 4.0 apresentam potencial para aumentar a flexibilidade, a velocidade, a produtividade e a qualidade dos processos de produção [8].

\section{TECNOLOGIAS HABILITADORAS}

Agora que já descreveu-se os principais fatores que obrigaram as indústrias a abrir mão de suas culturas iniciais e que ao longo dos anos continuaram com a necessidade de saírem de suas zonas de conforto para manter-se em um nível competitivo, garantir sua sobrevivência, mudar as condições de trabalho de seus empregados, melhorar a qualidade de seus produtos e serviços. Observou-se o quão importante foram todas essas revoluções e que estamos agora partindo para uma nova revolução, a indústria 4.0. É apresentado a seguir, as 9 principais tecnologias que habilitam a revolução 4.0, segundo o relatório do [9].

As principais tecnologias habilitadoras desenvolvidas ou em desenvolvimento, são capazes de implementar no universo industrial e social parte das mudanças que as bases da quarta revolução propõe e elas tem gerado maior impacto para indústria e sociedade. São elas:

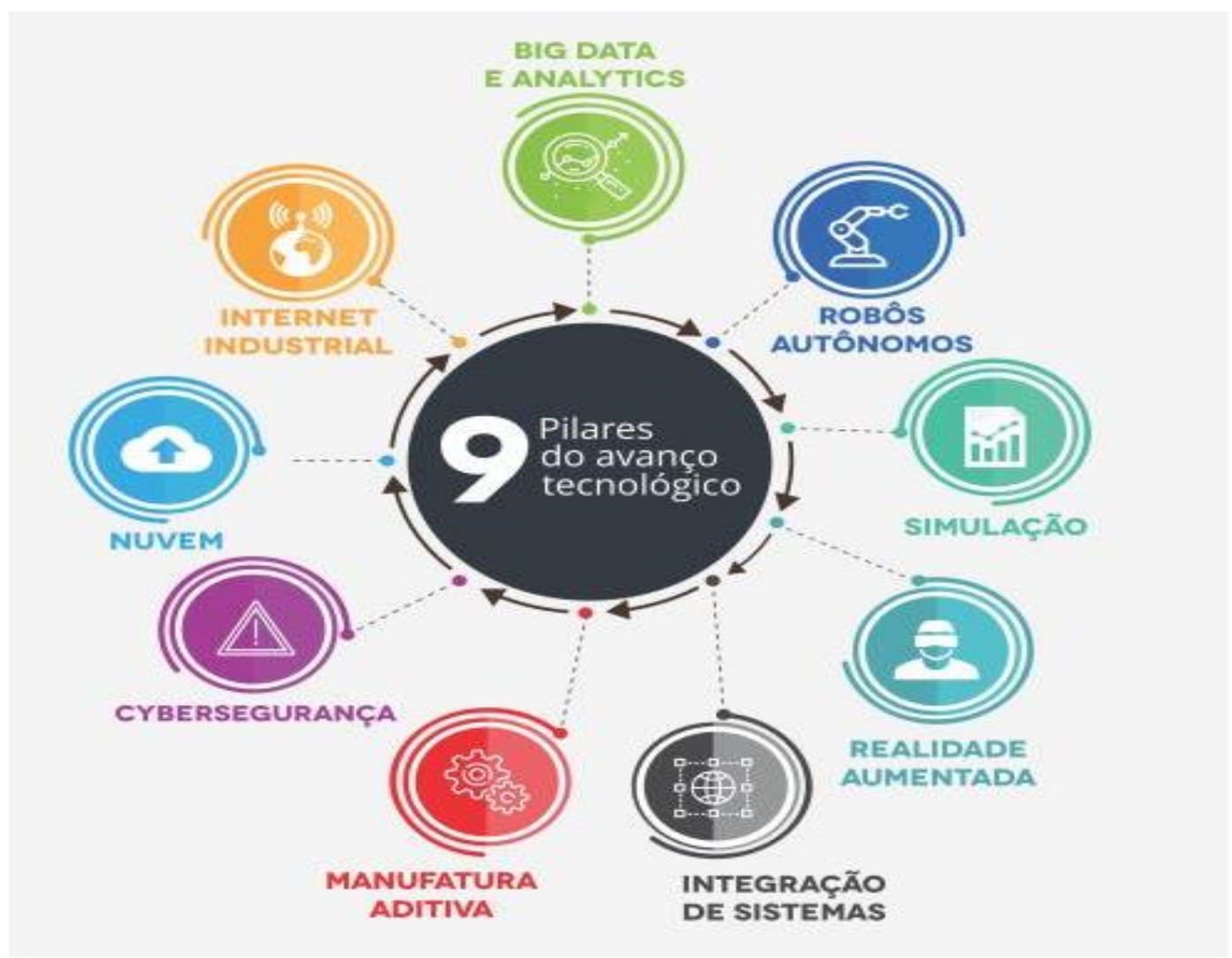

Figura 2: Tecnologias Habilitadoras.

Fonte: Adaptado de [9].

1 - Internet Industrial das Coisas: A Internet das Coisas nada mais é que uma extensão da Internet atual, que proporciona aos objetos do dia-a-dia (quaisquer que sejam), mas com capacidade computacional e de comunicação, se conectarem à internet. A conexão com a rede mundial de computadores viabilizará, primeiro, controlar remotamente os objetos e, segundo, permitir que os próprios objetos sejam acessados como provedores e serviços [10].

$\mathrm{Na}$ indústria 4.0, a Internet das Coisas auxilia na união entre os ambientes virtual e físico, no que resulta o ambiente cyber-físico e esse processo vem sendo chamado de Internet Industrial das Coisas (do inglês, Industrial Internet of Things). Ela também é responsável pela criação de redes inteligentes entre máquinas, 
processos, sistemas de comunicação e produtos durante todo seu ciclo de vida.

A IIoT contribui bastante na agilidade de tomadas de decisão por fornecer dados em tempo real, baseados nas informações que são compartilhadas pela rede inteligente, otimizando os tempos de produção e logística, aumentando a qualidade dos produtos e reduzindo gastos de energia.

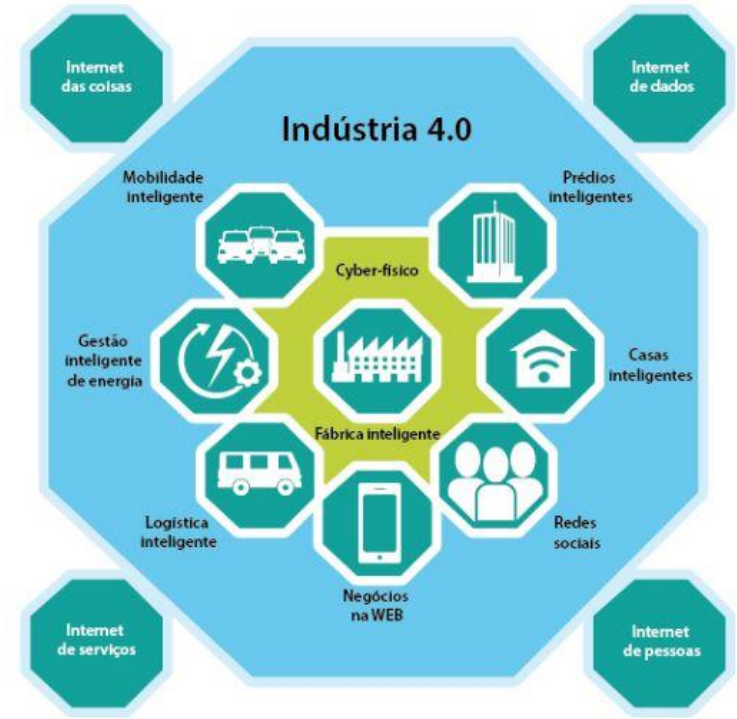

Figura 3: Conectividade IIoT.

Fonte: Adaptado de [1].

2 - Computação em Nuvem: Métodos tradicionais de armazenamento e compartilhamento de arquivos tem perdido forças na última década, a internet trouxe vários benefícios e um deles é a Computação em Nuvem (do inglês, Cloud Computing) que surgiu com o objetivo de simplificar o panorama entre o usuário e software.

Para [11] computação em nuvem: "Contempla a criação de modelos para acesso ubíquo, conveniente e sob demanda a diversos recursos computacionais compartilhados (como redes, servidores, dispositivos de armazenamento, aplicações e serviços) rapidamente fornecidos e lançados com o mínimo de gerência ou interação com provedores de serviços. Permite oferecer novos serviços e infraestruturas para software".

Pode-se dizer que nuvem é um recipiente de recursos construído para se adequar as necessidades do cliente em questões de armazenamento de dados, ficando disponíveis para acesso a qualquer hora e lugar, em tempo real através da internet.

Empresas já estão usando softwares e análises baseadas em nuvem, mas com a Indústria 4.0 um maior número de tarefas relacionadas a produção requer um maior compartilhamento de dados entre locais e empresas. Ao mesmo tempo, os desempenhos das tecnologias nas nuvens melhorarão, atingindo tempos de reação e de alguns milissegundos. Como resultado, os dados e a funcionalidade das máquinas serão cada vez mais implementados na nuvem, permitindo mais serviços orientados a dados para sistemas de produção. Até mesmo sistemas que monitoram e controlam processos podem se tornar baseados em nuvem [9].

3 - Big Data: Na indústria conectada do ambiente Indústria 4.0, os equipamentos, máquinas e processos estão continuamente gerando dados, que trafegam até os sistemas de gestão, e consequentemente criando um enorme volume de informação. Em tecnologia da informação, esse grande volume é chamado de Big Data. Diz-se que o Big Data se baseia em 5 V's: Velocidade, Volume, Variedade, Veracidade e Valor [12].

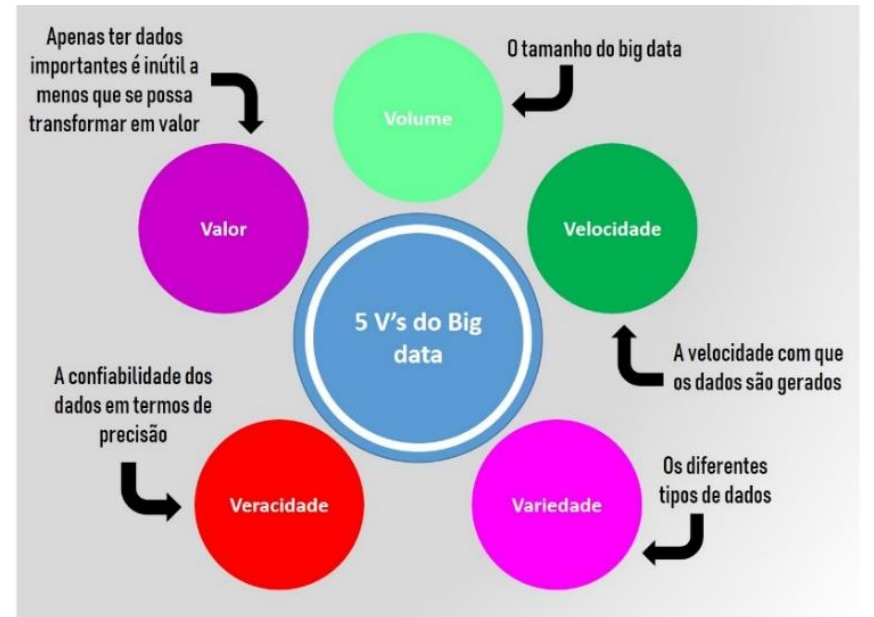

Figura 4: 5 V's do Big data.

Fonte: Adaptado de [13].

Para [14], o Big Data atua na diminuição de erros na produção, redução de custos, operações com melhor desempenho, planejamento estratégico mais embasado por parte dos gestores e criação de sistemas preditivos para manutenção de máquinas.

4 - Robôs Autônomos: Os robôs são utilizados para substituir o ser humano na execução de atividades em locais insalubres e que põe em risco a saúde do homem. No âmbito industrial, os robôs vem colaborando no aumento da produtividade, na qualidade dos produtos, na redução do consumo de energia, e têm evitado riscos à saúde e segurança do trabalhador.

$\mathrm{Na}$ indústria 4.0, os robôs autônomos tendem a assumir, cada vez mais, a execução de tarefas padronizadas e, até mesmo, trabalhos mais complicados. Ele vão passar a executar o mais difícil, enquanto o funcionário apenas atuará para complementar a atividade. Os robôs podem, inclusive, aprender como calcular o melhor trajeto entre um ponto e outro, pois têm um grau de autonomia capaz de ajustá-los a qualquer realidade. Mas vale a pena ressaltar que esse trabalho conjunto não pode ser feito por um robô qualquer, mas, sim, por um robô colaborativo que não expõe o ser humano a riscos. Quando ele percebe que o profissional vai interagir, ele age de uma maneira segura, e quando entende que o ser humano se afastou, passa atuar de outra maneira [12].

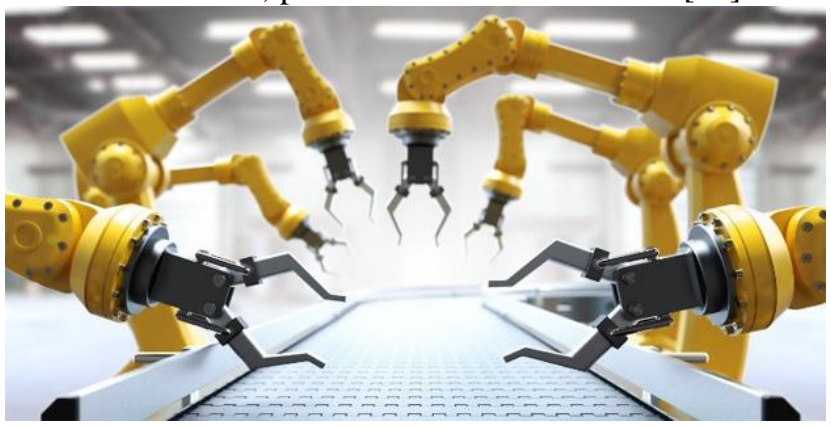

Figura 5: Robôs Autônomos.

Fonte: [21].

5 - Manufatura Aditiva: A manufatura aditiva - MA (ou do inglês: Additive Manufacturing - AM), também conhecida como impressão em 3D, refere-se a processos usados para criar um objeto tridimensional, em que camadas de material são formados sob controle de computador. Os objetos podem ser de qualquer forma ou geometria e são produzidos usando dados de modelo digital 3D ou outra fonte eletrônica de dados, como um arquivo AMF (Additive Manufacturing File). Assim, ao contrário do material ser removido, como ocorre no processo de usinagem 
convencional, a impressão 3D ou MA constrói um objeto tridimensional a partir do modelo CAD ou arquivo AMF, adicionando sucessivamente material camada a camada [12].

$\mathrm{Na}$ indústria, a manufatura aditiva está contribuindo para uma maior flexibilidade da indústria, a fim de trazer novas soluções de produção (produtos mais flexíveis e complexos com baixo custo adicional) ou formando uma nova cadeia de fornecimento, com redução de estoques, prazos de entrega mais curtos ou a combinação de ambos [4].

6 - Simulação Digital: Na indústria $4.0 \mathrm{ou}$ em qualquer outro segmento, consiste na utilização de ferramentas e softwares de modelagem tridimensional que simula o ciclo de um determinado processo, possibilitando criar protótipos virtuais, maximizando o processo de produção. Técnica que baseada em modelos matemáticos e representações $3 \mathrm{D}$ de máquinas, equipamentos e processos que permite testar e otimizar processos e produtos ainda na fase de concepção. Deste conceito, encontramos alguns termos já conhecidos no mercado, como Gêmeo Digital (Digital Twin), Gêmeo Virtual, entre outros. A Simulação Digital pode ser utilizada também na simulação de variáveis reais de processos produtivos, de maneira que sejam testados diversos modelos matemáticos dos processos, para que se encontre o melhor nível de otimização no tempo de execução e no uso dos recursos, insumos e energia [12].

7 - Integração de Sistemas: Consiste na utilização de sistemas de TI que integram uma cadeia de valor automatizada, por meio da digitalização de dados. Essa integração possibilita que os dados criados no momento de atendimento ao cliente percorram todo processo de produtivo e logístico, possibilitando a gestão de dados de produtos personalizados. Por outro lado, no ambiente da indústria, os dados trafegam no sentido vertical, desde os sensores e atuadores do chão de fábrica, até os sistemas de ERP que fazem a gestão da empresa [12].

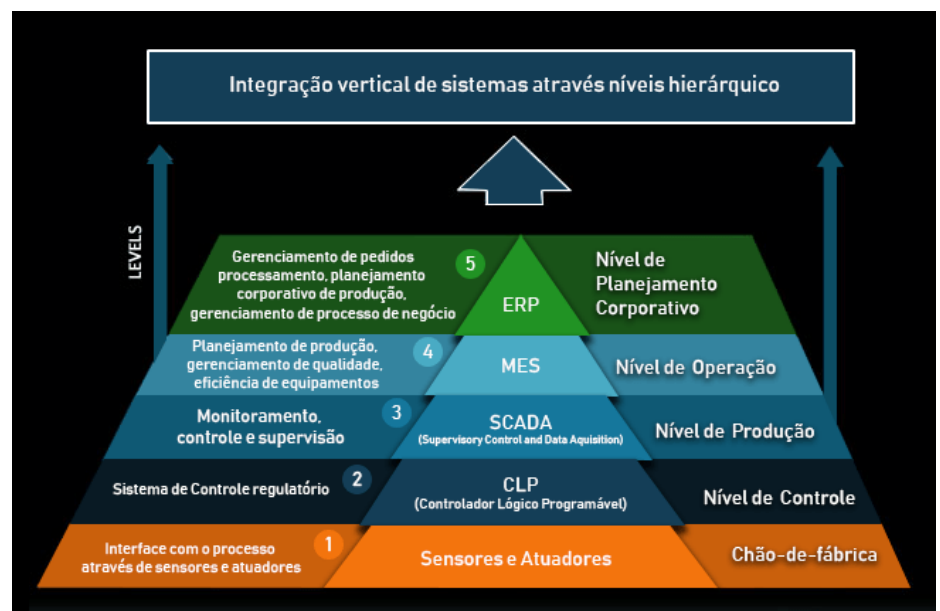

Figura 4: Integração Vertical de Sistemas. Fonte: [22].

8 - Realidade Aumentada: A realidade aumentada - RA (ou do inglês: Augmented Reality - AR) é uma visão ampliada de elementos físicos do mundo real, cujos são "aumentados" por entrada sensorial gerada por computador, como som, vídeo, gráficos ou dados GPS. Está relacionado a um conceito mais geral, chamado de realidade mediada por computador, em que uma visão da realidade é modificada (possivelmente até diminuída em vez de aumentada) por um computador. A realidade aumentada, aumenta a percepção atual da realidade, enquanto, em contraste, a realidade virtual substituiu o mundo real por uma simulada. Na indústria 4.0, as aplicações da Realidade Aumentada podem ir desde uma aplicação como suporte aos processos de montagem nas linhas de produção, como ferramenta auxiliar para a manutenção remota, até aplicação em treinamentos de técnicos em novos equipamentos e processos [12].

9 - Segurança Cibernética: Com a inserção do conceito e conectividade das tecnologias da indústria 4.0, o volume de dados cresce de maneira exorbitante, logo o armazenamento desses dados na nuvem exige uma grande atenção com relação à segurança. Para garantir a confiabilidade e segurança dessas informações, sistemas avançados de criptografia são desenvolvidas com maior frequência. Atualmente, sistemas de controle industrial que se conectam permanentemente via TCP / IP e Ethernet são uma visão comum, assim como o uso de sistemas sem fio padronizados. Todos esses protocolos foram desenvolvidos e analisados detalhadamente, e eles oferecem a maturidade e a confiabilidade que a Indústria 4.0 exige [12].

\section{GRAU DE MATURIDADE DA INDÚSTRIA 4.0}

A agilidade é umas das características essenciais para que as indústrias alcancem um patamar elevado e é um fator determinante para o sucesso. Com a chegada do conceito da quarta revolução industrial, vimos que é possível que as empresas alcancem o nível de excelência, com a integração das tecnologias que o termo proporciona. Mas aderir dessas tecnologias não é tarefa simples, pois a Indústria 4.0 é um conceito tecnológico muito bem evoluído, eficiente e entrega produtos bem mais alinhados para seus clientes, o que pode ir muito além do que sua empresa oferece hoje. Sendo assim, é importante saber em que nível sua organização se encontra atualmente.

Um estudo realizado pela Academia Nacional de Ciência e Engenharia Alemã (ACATECH), oferece um modelo de maturidade que auxilia as empresas na adaptação dos recursos que elas possuem hoje para se integrar na nova revolução, descobrindo qual seu nível de maturidade focando em verificar qual sua proximidade à ela.

O caminho para a indústria 4.0 é diferente para cada empresa baseando-se em seus princípios, deve ser analisado seus objetivos estratégicos para os próximos anos, as tecnologias que eles já utilizam e o modo como operam. O estudo realizado dentro desses quesitos determina com propriedade quais as capacidades que precisam adquirir e o que precisa ser descartado a fim de introduzir uma integração com êxito.

\section{V.1 ESTÁGIOS DE DESENVOLVIMENTO}

O conceito da quarta revolução industrial está ligada diretamente a modernização dos processos industriais, como a renovação significativa de suas competências e capacidades tecnológicas, envolvendo grandes mudanças nas organizações.

Essa transformação é de extrema complexidade e geralmente leva vários anos para ser concluída. É necessário planejamento qualificado e implementação adequada, de modo que gere impactos positivos sobre a lucratividade, tornando o negócio eficiente e crescente à cada estágio da transição.

Hoje, as empresas ainda estão enfrentando desafios de criar condições básicas para a Indústria 4.0. Assim, o caminho do desenvolvimento começa com a digitalização. Embora a digitalização não faça parte indústria 4.0, a informatização e a conectividade são requisitos básicos para sua implementação. 
Esses dois estágios iniciais são seguidos por quatro estágios adicionais nos quais os recursos para a Indústria 4.0 são desenvolvidos [15]. Conforme pode ser observado na Figura 5 a seguir.

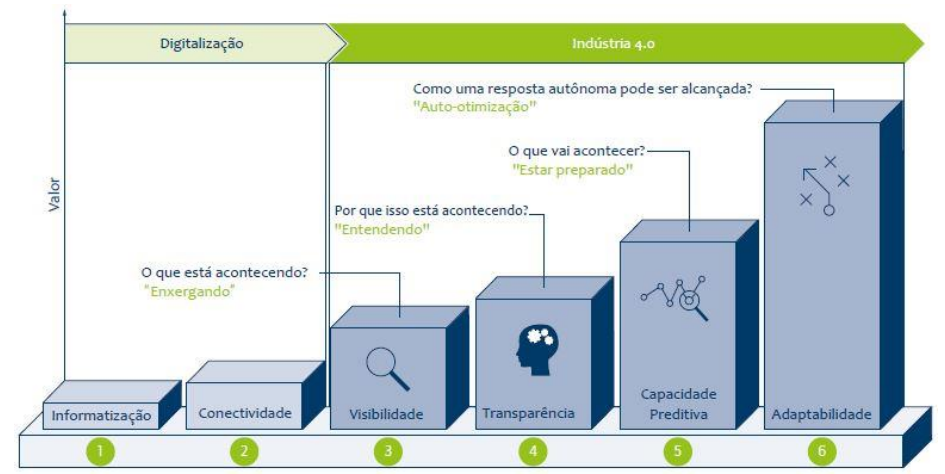

Figura 5: Estágios de desenvolvimento para Indústria 4.0. Fonte: Adaptado de [15].

\section{V.1.1 ESTÁGIO 1: INFORMATIZAÇÃO}

O primeiro estágio no caminho da maturidade à Indústria 4.0 contempla na utilização de tecnologias que são base para a digitalização. São utilizadas diferentes tecnologias que operam de forma isolada uma das outras e esta etapa já está bem desenvolvida em grande parte das indústrias. Ela proporciona benefícios como: a possibilidade de fabricação barata a padrões bem mais elevados, atua na execução de tarefas repetitivas e de rotina possibilitando um maior grau de precisão. Um exemplo são as máquinas CNC [15].

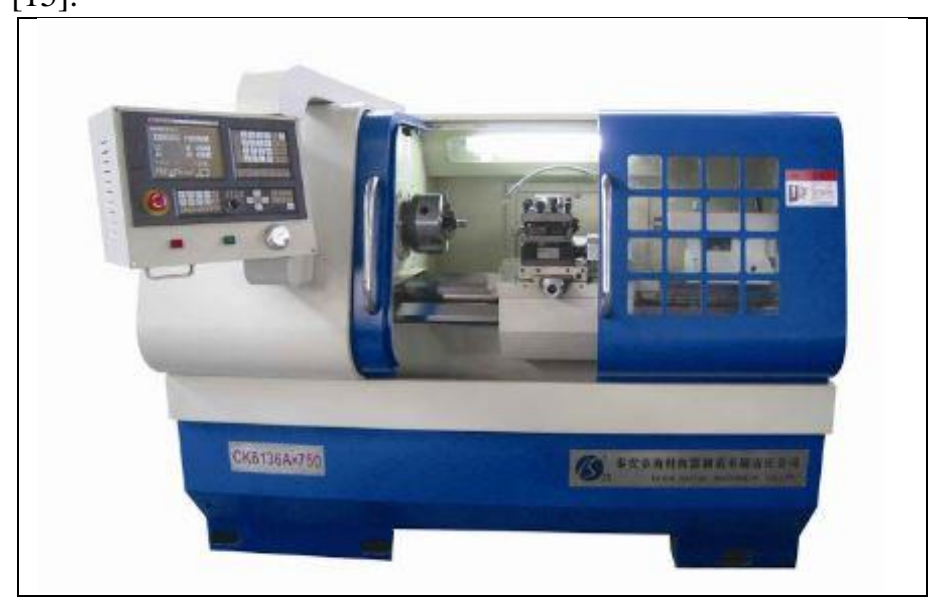

Figura 6: Máquina CNC.

Fonte: [16].

\section{V.1.2 ESTÁGIO 2: CONECTIVIDADE}

No segundo estágio, a implantação isolada da Tecnologia da Informação é substituído por componentes conectados. As aplicações e tecnologias estão totalmente ligadas umas às outras e refletem os principais processos da empresa. Os principais benefícios dessa etapa são a interoperabilidade e conectividade entre os sistemas, porém ainda não possui integração total das tecnologias da informação com as de operação. Uma forte característica desse estágio é a possibilidade de compartilhamento de informações operacionais através do protocolo de Internet (IP Internet Protocol), que é uma peça fundamental para a Internet das Coisas. Os projetos de engenharia nesta etapa possuem mais agilidade e eficiência, uma vez que criado, seus dados são empurrados para produção e após finalizado sua confirmação pode ser fornecida automaticamente em tempo real [15].

\section{V.1.3 ESTÁGIO 3: VISIBILIDADE}

No estágio da visibilidade, os sensores IoT permitem que os processos sejam capturados por diferentes pontos de dados do início ao fim. Os eventos e estados podem ser gravados através destes sensores, fornecendo visibilidade do processo em toda a empresa por meio da conexão entre tecnologia da informação e automação, e este não se limita apenas nas áreas individuais como anteriormente. Tornando possível manter um modelo digital atualizado de fábricas a todo momento. Esse modelo é denominado como "sombra digital da indústria", com objetivo de indicar a situação atual dos processos, máquinas, materiais e pessoas da empresa, em outras palavras, um mapeamento de todas as informações geradas com ágil tempo de reposta, permitindo uma análise mais robusta de fatores críticos que podem prejudicar os projetos e processos da empresa. A visão unificada dos recursos em tempo real, rastreabilidade dos eventos e estados, tomadas de decisões baseadas em informações precisas são os principais benefícios do terceiro estágio [15].

\section{V.1.4 ESTÁGIO 4: TRANSPARÊNCIA}

Vimos que no terceiro estágio envolve a criação da "sombra digital", que mostra a situação atual da empresa através da captura dos dados, entendermos o que está acontecendo com a empresa e decidir quais ações necessárias devem ser tomadas. Já no quarto estágio é para tratarmos dos dados coletados anteriormente por meio de análises avançadas, permitindo identificar e interpretar as interações realizadas na sombra digital. Como na maioria das vezes o volume de dados são grandes, é necessário a utilização de técnicas do conceito Big Data para identificar os dados de massa que não conseguem mais ser processados e analisados usando processos de análise convencionais de negócio. O conceito Big Data é componente chave desta etapa, ele é aplicado juntamente à sistemas como ERP (Enterprise Resource Planning) ou MES (Manufacturing Execution Systems). A característica desse estágio é o monitoramento online dos equipamentos, máquinas e processos que emitem alertas quando ocorre algo fora do padrão, tornando um requisito para manutenção preditiva [15].

\section{V.1.5 ESTÁGIO 5: CAPACIDADE PREDITIVA}

Esse estágio baseia-se na etapa da transparência. Através dos dados obtidos e tratados, a empresa é capaz de simular cenários futuros e analisar quais são os mais prováveis, a fim de conseguir agir antecipadamente à eventos que podem ser prejudicial ao projeto. A capacidade preditiva reduz o número de eventos inesperados causados, por exemplo, interrupções ou intermitência nos processos, máquinas e equipamentos, permitindo uma operação mais robusta do negócio e eventos como esses podem ser identificados por meio de sinalizações antecipadas de problemas recorrentes para serem evitadas em tempo útil, mas as ações tomadas nesta etapa ainda são manuais [15].

\section{V.1.6 ESTÁGIO 6: ADAPTABILIDADE}

Por fim a última etapa para se alcançar a maturidade de indústria 4.0 é a adaptabilidade. A capacidade preditiva é um requisito fundamental para ações e tomadas de decisões 
automatizadas, pois baseados nos dados coletados no quinto estágio, o sexto estágio fornece uma adaptação contínua que permite que uma determinada empresa delegue certas decisões para os Sistemas de TI, para que ele adapte as mudanças do ambiente de negócios rapidamente. No entanto, o grau de adaptabilidade depende da complexidade das decisões e da relação custobenefício. $\mathrm{O}$ objetivo da adaptabilidade é alcançado quando uma empresa é capaz de utilizar os dados coletados nos estágios anteriores para tomadas de decisões com melhores resultados possíveis no menor tempo possível, para aplicar as medidas correspondentes de maneira autônoma, ou seja, sem intervenção humana [15].

Nessa fase, a empresa será capaz de identificar e solucionar problemas, conseguindo atender com flexibilidade de acordo com as mudanças nas demandas de novos produtos e serviços.

Portanto, com a adoção da manufatura digital é possível ter benefícios como: reduzir os ciclos desenvolvimento do produto e custos da manufatura, acelerar o tempo para comercialização, aumentar a qualidade do produto e melhorar na disseminação do conhecimento do produto [17].

\section{AUTOMAÇÃO NA INDÚSTRIA 4.0}

A automação é uma das tecnologias que são base para a quarta revolução. A robótica por si só ou aplicada no conceito de automação industrial, é uma característica já estabelecida na terceira revolução de indústria. Isso tem confundido algumas pessoas com relação ao conceito da Indústria 4.0, pois no entendimento delas, ter automação em seu ambiente industrial, já torna uma empresa habilitada ao novo conceito.

Quando falamos de Indústria 4.0, significa que já alcançamos o maior nível de automação industrial e a melhor eficácia de produção, este faz parte do $1^{\circ}$ estágio do nível de maturidade para desenvolvimento de integração do conceito.

Segundo [20], existem diversos tipos de sistemas de automação industrial para atender diferentes exigências e demandas de mercado. Por isso, no intuito de automatizar, as indústrias, antes de tudo, entender o que é a Indústria 4.0, depois projetar, avaliar e adquirir componentes automatizados a fim de construir um sistema automatizado. É por isso que todos os tipos de necessidades podem ser colocados sob um sistema de automação industrial, fazendo com que haja grande adequação a diferentes demandas. Em outras palavras, a customização de produtos, uma das principais caraterísticas de resultado da Indústria 4.0 .

\section{INDÚSTRIA 4.0 APLICADO EM EMPRESAS BRASILEIRAS}

No Brasil, algumas empresas já estão se integrando na nova revolução, seja para tornar-se referência no mercado garantindo sua competitividade, como para melhorias nas condições de trabalho, agilidade e customização de produtos, conquistando seu público alvo que são seus clientes.

A Embraer tem utilizado da tecnologia de simulação, utilizando treinamento virtual de decolagem em 3D, o que os trabalhadores fariam no chão de fábrica um ano antes do início da produção. O projeto teve 12 mil horas de testes antes das aeronaves decolarem. Defeitos que, normalmente, seriam detectados somente com o avião no ar, foram resolvidos ainda na fase de produção. Em sua linha de montagem, os operadores utilizam computadores e tablets com tecnologia de realidade aumentada e, em caso de dúvida, há sempre um vídeo para explicar como realizar a operação. Com todos os ganhos da digitalização, o tempo de montagem já caiu 25\% [18].

A ThyssenKrupp, um grupo industrial diversificado de alta tecnologia da Alemanha, inaugurou uma fábrica de componentes automotivos no Brasil em Poço de Caldas (MG). Todo seu processo produtivo segue o conceito de fábrica inteligente, suas tecnologias modernas estão combinadas e seus processos estão interconectados, é uma caraterística dos sistemas cyber-físico representando o futuro dos processos de manufatura [19].

Atualmente, a empresa automobilística Volkswagen do Brasil está investindo em robôs colaborativos, máquinas inteligentes, postos de trabalho que se comunicam interagindo com o veículo em processamento, fábrica digital, sistemas de rastreabilidade, logística inteligente, prototipagem em 3D, entre outros conceitos avançados que fazem parte da Indústria 4.0, melhorando seu nível de produção, aumentando a eficiência operacional, eliminando erros e reduzindo custos, com o objetivo de desenvolver uma fábrica inteligente.

\section{CONCLUSÃO}

Ao longo dos anos foi possível a observação e a integração mediante a grandes revoluções na indústria, a necessidade de melhorias em suas culturas e segmentos, trouxe consigo invenções que conseguiram supri-las com propriedade, deixando sua marca na história. Estamos diante de uma nova exigência, a transformação digital para entrarmos no conceito da quarta revolução industrial, o que não se caracteriza apenas na utilização de robôs. A indústria 4.0 vai muito além da utilização da robótica, e muitas pessoas possuem uma concepção errônea em relação a isso. Elas acreditam que pelo fato da empresa possuir robôs como recursos em seu ambiente industrial, à torna uma empresa aplicada ao conceito. Porém, a robótica é um dos recursos que à habilitam. A Indústria 4.0 é basicamente a união de várias tecnologias que conseguem comunicar-se entre si, no que se presume "fábricas inteligentes", proporcionando para a indústria, importantes benefícios como a redução de manutenção de equipamentos, customização de produtos, aumento na produtividade, ganhos em qualidade, sustentabilidade, redução de custos, entre outros. As empresas que conseguem realizar esse feito, tornam-se referência no atual mercado, garantem sua sobrevivência e crescimento de seu nível de competitividade. E este processo de transformação já se tornou simplificado para as empresas, estudos realizados como na ACATECH, auxiliam nesse processo migratório, avaliando o nível de maturidade da empresa, permitindo uma análise da situação atual e de qual rumo deve tomar para se integrar nesse novo conceito tecnológico. Existem também avaliações online de maturidade na internet, como a que foi desenvolvida pelo Serviço Nacional de Aprendizagem Industrial (SENAI) que segue esse mesmo modelo. $\mathrm{O}$ fato é que essa revolução já uma realidade a ser adota, as indústrias que querem alcançar o sucesso e sobreviver nessa nova realidade do mercado, deve o quanto antes se adequar a essas tecnologias se não quiser perder espaço para seus concorrentes na corrida para o sucesso.

\section{REFERÊNCIAS}

[1] Deloitte Touche Tohmatsu Limited Industry 4.0 Challenges and solutions for the digital transformation and use of exponencial 
technologies,

2014.

Disponível

em: https://www2.deloitte.com/content/dam/Deloitte/ch/Documents/m anufacturing/ch-en-manufacturing-industry-4-0-24102014.pdf.

Acesso em: 20 de abril de 2019.

[2] R. Davies, Industry 4.0: Digitalisation for productivity and growth, 2015. Acesso em: 20 de abril de 2019.

[3] R. Lemos, Indústria 4.0? A nova revolução, 2018. Acesso em: 11 de abril de 2019.

[4] B. Gomes, Panorama da Inovação: Indústria 4.0, 2016. Acesso em: 11 de abril de 2019.

[5] J. Bezerra, Segunda Revolução Industrial, 2018. Acesso em: 23 de março de 2019.

[6] D. Silva, Indústria 4.0 com foco nos sistemas Cyber Físicos, 2018. Acesso em: 12 de abril de 2019.

[7] K. Schwab, The Fourth Industrial Revolution, 2016. Acesso em: 20 de abril de 2019.

[8] G. Junior, P. Saltorato, Impactos da Indústria 4.0 na Organização do Trabalho: Uma revisão sistemática da literatura, 2017. Acesso em: 20 de abril de 2019.

[9] Boston Consulting Group, Industry 4.0: The future of productivity and growth in manufacturing industries, 2015. Acesso em: 20 de abril de 2019.

[10] B. Santos et al, Internet das Coisas: da Teoria à Prática, 2016. Acesso em: 22 de abril de 2019.

[11] M. Steda, Tecnologias da Informação e Território: Políticas para o setor de software no Brasil, 2015. Acesso em: 28 de abril de 2019.

[12] P. Santos, Revista Elevador Brasil - Edição 151, p. 76, 2018. Acesso em: 22 de abril de 2019.

[13] D. Silva, Bid data analytics: Domine o conceito e aumente a eficiência da sua indústria, 2017. Disponível em: https://www.logiquesistemas.com.br/blog/big-data-analytics.

Acesso em: 22 de abril de 2019.

[14] T. Koike, O Big Data na Indústria 4.0: Qual sua importância? 2018. Disponível em: https://www.pollux.com.br/blog/big-datana-industria-4-0-qual-sua-importancia.

Acesso em: 22 de abril de 2019.

[15] G. Schuh; et. al, Industrie 4.0 Maturity Index: Managing the Digital Transformation of Companies (ACATECH STUDY), 2017.

Acesso em: 22 de abril de 2019.

[16] P. Mishra, What is CNC Machine - Main Parts, Working, Block Diagram, 2017.

Acesso em: 5 de maio de 2019.
[17] P. Carli, M. Delamaro, Implantação da Manufatura Digital numa empresa: Identificandos os fatores críticos de sucesso, 2007. Disponível em: http://www.abepro.org.br/biblioteca/ENEGEP2007_TR570438_9 950.pdf

Acesso em: 05 de maio de 2019.

[18] J. Teles, Indústria 4.0 - Tudo que você precisa saber sobre a Quarta Revolução Industrial, 2017. Disponível em: https://engeteles.com.br/industria-4-0/

Acesso em: 07 de maio de 2019.

[19] Estadão Conteúdo, Para garantir competitividade, empresas no Brasil se adaptam à industria 4.0, 2018. Disponível em: https://www.gazetadopovo.com.br/economia/novaeconomia/para-garantir-competitividade-empresas-no-brasil-seadaptam-a-industria-40-1fdb7cnqjak4gh98hofy8k6ut/ Acesso em: 08 de maio de 2019.

[20] Redação FISPAL Tecnologia, Automação é fundamental para a Indústria 4.0, 2017. Disponível em: https://digital.fispaltecnologia.com.br/automacao-industria-4-0/ Acesso em: 11 de maio de 2019.

[21] G. Felix, A Indústria 4.0: O que você precisa saber para garantir seu emprego!, 2018. Disponível em: http://www.excelenciaoperacional.blog.br/2018/08/24/a-industria4-0-o-que-voce-precisa-saber-para-garantir-seu-emprego/ Acesso em: 12 de maio de 2019.

[22] W. Santana, Pilares da Indústria 4.0 - Sistemas de integração horizontal e vertical, 2018. Disponível em: https://rvsis.com.br/index.php/news/78-pilares-4-d-9 Acesso em: 12 de maio de 2019. 